\title{
THE MATHEMATICAL ANALYSIS OF DEMANDS FOR RAILWAY PASSENGER TRANSPORT IN KOSOVO
}

\author{
MAZREKAJ Ramadan', SHALA Ahmet ${ }^{1 *}$ \\ ${ }^{1}$ Faculty of Mechanical Engineering, University of Prishtina, Bregu i Diellit, p.n. 10000 Prishtina, Kosovo \\ e-mail: ahmet.shala@uni-pr.edu
}

\begin{abstract}
The purpose of this paper is to analyse the railway transport of passengers in Kosovo, to determine its intensity and structure, to analyse which factors have the greatest impact on the demand for regular rail transport. Furthermore, the paper will examine which trend, which model fits best in moving this mode of transport based on data from 2011 to 2019, and then predict future trends in transport demand. The existence and strength of the dependence among the selected factors, which are assumed to have an impact on passenger rail transport will be examined by the mathematical method of regression analysis.
\end{abstract}

KEYWORDS: railway passenger transport, quantitative forecasting methods, time series analysis, regression analysis.

\section{Introduction}

Rail transport in Kosovo takes place on the rail network with a length of 333,951 kilometres (207,507 miles) up to 105,784 kilometres $(65,731$ miles), while the industrial line covers 103,4 $\mathrm{km}$ (64 miles). Kosovo Railways is a public sector property, where the state has the right to make decisions in all administrative actions through the Ministry of Economic Development [14].

Rail transport is one of the safest transport lines in Kosovo. Its infrastructure and vehicles are technically safer than other means of transport. However, they are immune to harsh weather conditions such as snow, fog etc. In addition, rail transport is more environmentally friendly as well as since they are fuelled by Diesel Electric locomotives as their primary fuel source.

Kosovo Railways now has eight diesel locomotives and four Thermos Motoric. They have the ability to tow 17 wagons, 16 of which are for passengers and the rest are for freight. Kosovo Railways has an important role to play in transporting passengers and freight. In 2005, according to one estimate, there were 870 passengers per day who had chosen trains as a means of transport. In 2006, there was an increase of $26.56 \%$ more than in 2005 , which means that there was an increase in 1100 daily commuters. In 2007, the number of passengers traveling by train in one day was 1143 or $3.91 \%$ more than in 2006. In 2008, there was a decrease in the number of passengers by $18.77 \%$ compared to 2007 . Average number of passengers per day during 2009 was 1026 or $10.51 \%$ more than in 2008. There was also an increase in passengers per day in 2010 from 1032 or $0.61 \%$ compared to 2009. From 2011 to 2014 there was an increase in the number of passengers, but from 2014 to 2019 the number of passengers significantly decreased $[13,14]$. 

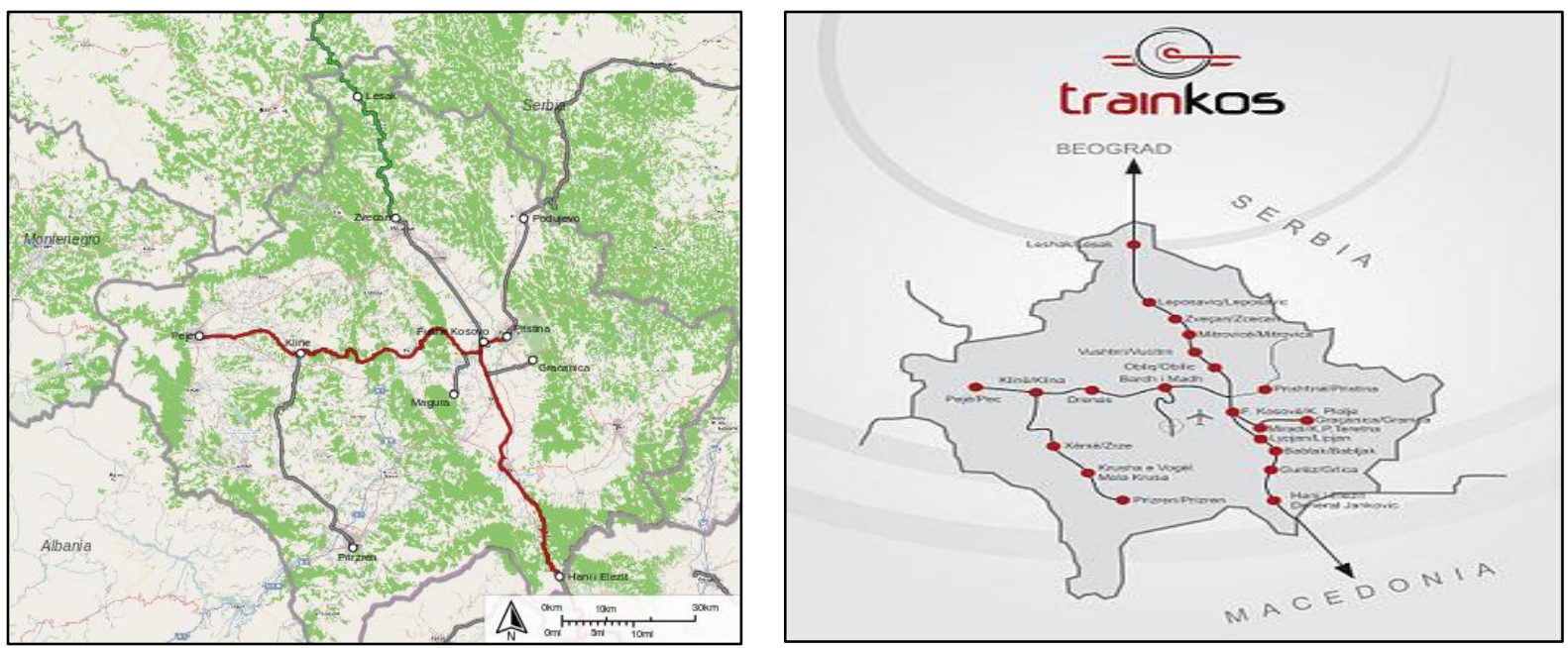

Fig. 1 Map of Kosovo railways [14]

\section{Request for Transportation of passengers in Railway transport in Kosovo}

\subsection{The Mathematical methods of analysis}

The quantitative methods of forecasting are used in this paper are: time series analysis, and regression analysis. Quantitative methods of prognosis first analyse the appearances of the upto-date movements or the resolution of the appearances that significantly affect the problem analysed, and then quantify the dependencies that exist between those representations $[4,6]$. These methods are based on a corresponding extension of the current trend, explain the movements in the past period and the reasons that caused these movements. Advances in the application of quantitative methods have resulted from the rapid development of computers and software that have enabled the use of large amounts of data, comparing different variants, and choosing the optimal solution.

Table 1. The data variables for the analysis of requests for rail passenger transport in the period 2011-2019 [13, 14

\begin{tabular}{|c|c|c|c|c|}
\hline Year & NPTR & NVR & NT & APK \\
\hline 2011 & 357730 & 170321 & 6 & 327 \\
\hline 2012 & 366550 & 176398 & 7 & 384 \\
\hline 2013 & 369270 & 222537 & 6 & 393 \\
\hline 2014 & 339580 & 236145 & 6 & 430 \\
\hline 2015 & 269150 & 281847 & 7 & 451 \\
\hline 2016 & 279210 & 260291 & 8 & 457 \\
\hline 2017 & 156620 & 273862 & 6 & 471 \\
\hline 2018 & 12030 & 280422 & 6 & 498 \\
\hline 2019 & 11024 & 291295 & 5 & 500 \\
\hline
\end{tabular}

Where: NPTR - Number of Passengers Transported by Railway Transport NVR - Number of Vehicles Registered

NT - Number of Trains

APK - Average Payment in Kosovo

Time series analysis is one of the most widely used methods of quantitative forecasting. For the prediction of rail transport of passengers in Kosovo with the help of time series analysis 
(Time series analysis - TSA), the MS Excel program was used, and the data of the passengers transported by railway transport (NPTR), besides this variable are presented in Table 1, data on variables to be analysed in regression analysis: passengers transported by rail, number of vehicles registered, number of trains, average wage in Kosovo. All data are given for the period from 2011 to 2019.

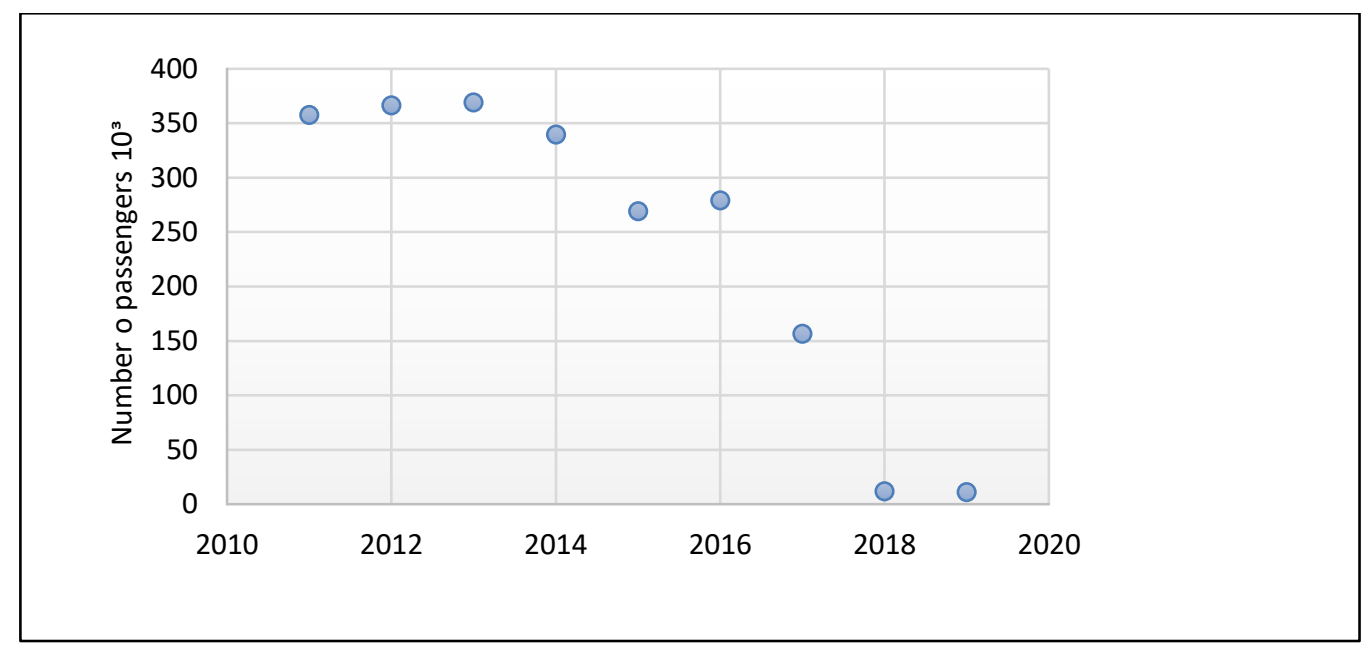

Fig. 2 Passengers transported by rail in Kosovo from 2011 to 2019

From 2011 to 2019 there is a permanent decrease in the number of passengers transported by rail transport in Kosovo, from 357730 in 2011, and 366550 in 2012 to 11024 in 2019.

To win the trend, it is necessary to transform the values of years variables (time expressed in years) into variables $X$ with values from 0 to 8 in advance. Figures 2-4 shows linear, parabolic, and exponential trends with the corresponding equations. For the linear, parabolic, and exponential trend equations sourced from the beginning of the period, explanations of the meaning of the parameters in the trend equations are presented, where $X=0$ for 2011 , unit $X$ is one year, and unit $\mathrm{Y}$ is a thousand passengers transported by rail transport $[6,11,12]$.

$$
\begin{gathered}
Y_{i}=\beta_{0}+\beta_{1} X_{i}+\varepsilon_{i} \\
\hat{Y}_{i}=b_{0}+b_{1} X_{i}
\end{gathered}
$$

Where:

$Y_{i}$ - Dependant variable.

$\beta_{0}$ - Interruption on the $\mathrm{Y}$-axis, in the population.

$\beta_{1}$ - Population slope coefficient.

$X_{i}$ - Independent variable.

$\varepsilon_{i}$ - Occasional error.

In the linear trend equation $Y=-4.8934 x+43.5866$, the parameter $a_{0}(43.587)$ represents the expected value trend in base year 2011 that reaches the value of 435866 passengers transported by rail in Kosovo. The value of parameter $\mathrm{a}_{\mathrm{o}}$ serves as a kind of trend model control, where there should be no large differences between the empirical value trends, but this is not the case here, because the difference of passengers is considerable. Parameter $\mathrm{a}_{1}(-4.8934)$ means that the number of passengers transported in Kosovo in the period estimated at the average of each year has decreased by 48934 passengers. 


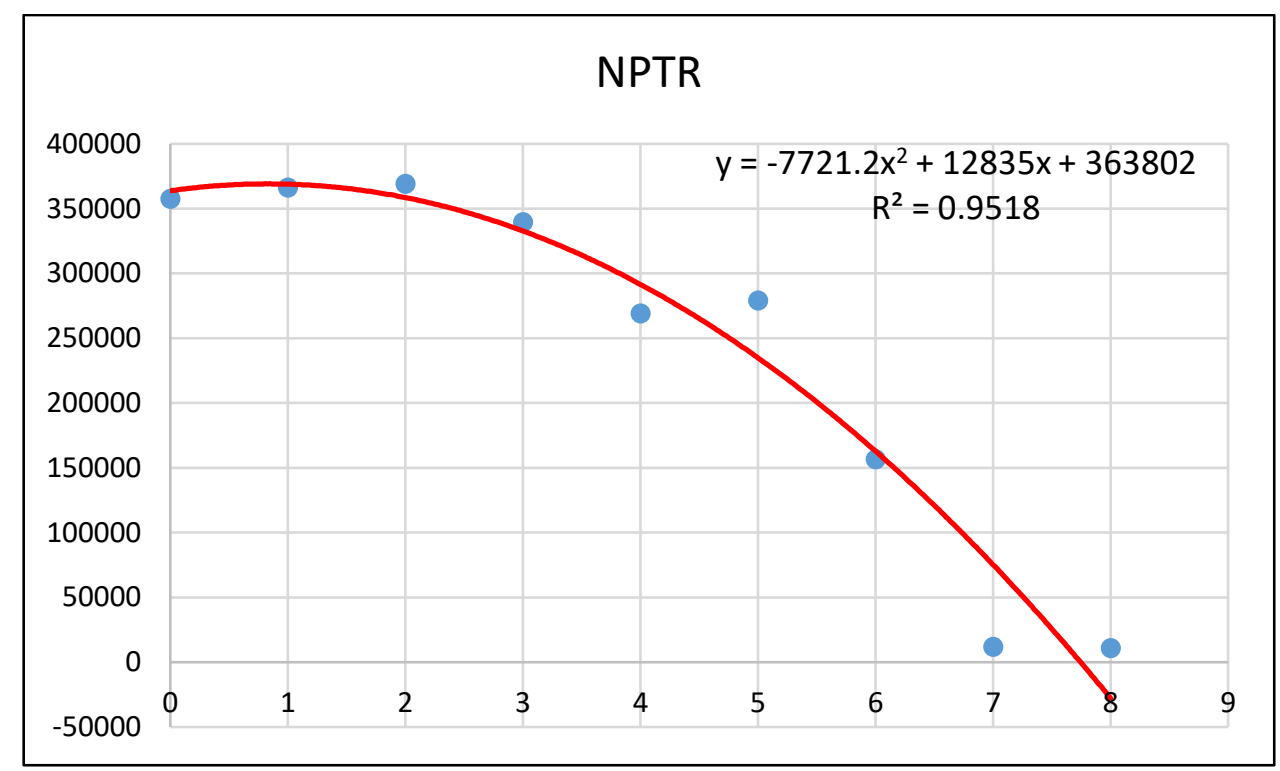

Fig. 3 Passengers transported by rail in the period 2011 to 2019 , and the polynomial trend

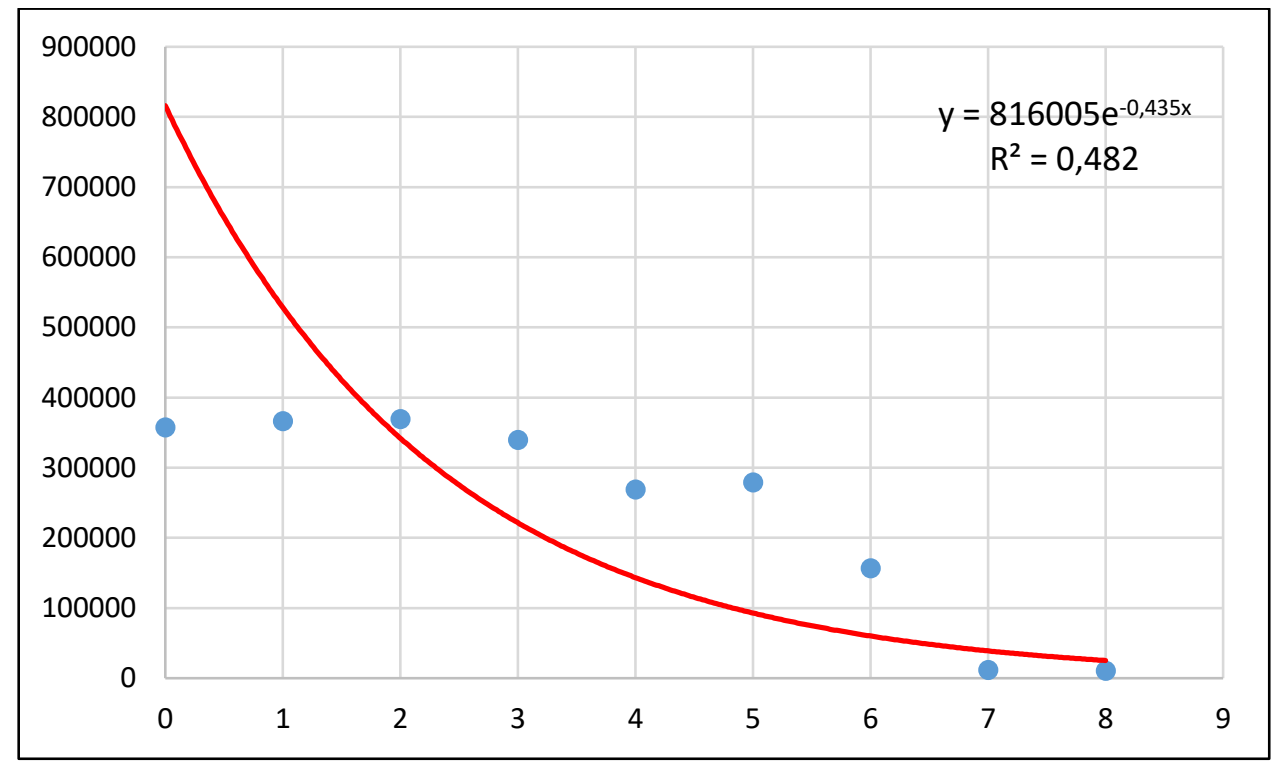

Fig. 4 Passengers transported by rail in the period 2011 to 2019, and the exponential trend

The obtained equation of the exponential trend is presented; $\mathrm{Y}=816005^{\wedge} \mathrm{e}^{\wedge}(-0.435 \mathrm{x})$ where parameter $a_{o}$ represents the value trend from source 2011, and is 816005 passengers transported. The parameter $a_{1}$ means that in the estimated period the number of passengers decreased per year. The obtained representative trends are determined on the basis of the coefficient of determination (indicator $\mathrm{R}^{2}$ ). For the third-degree parabolic trend, the indicator is 0.9518 , which means that $95.18 \%$ of the periodic changes in passenger transport in Kosovo from 2011 to 2019 explain the parabolic trend pattern. As the parabolic representation model is the largest, the third-degree parabolic equation will be used for the next prognosis.

Assuming that the number of passengers in the rail transport in Kosovo will continue to move according to the chosen parabolic trend, the expected extrapolation has predicted the values for the five-year period (Table 2), which is also evident in Figure 2. 
Table 2 Forecast of passenger transport in railway transport in Kosovo from 2014 to 2019

\begin{tabular}{|c|c|}
\hline Year & NPTR \\
\hline 2014 & 339580 \\
\hline 2015 & 269150 \\
\hline 2016 & 279210 \\
\hline 2017 & 156620 \\
\hline 2018 & 12030 \\
\hline
\end{tabular}

Making prognosis in conditions when Kosovo is in an unstable economic situation for which it is unknown until it will last, and it is unknown how long it will last, it is subject to error precisely because of uncertainty. Otherwise the recommendation is not to make long term forecasts, maximizing for the next half of the estimated period. Forecasting traffic using time series analysis, the dynamics of future traffic movements is particularly based on the past traffic movement.

However, for a better and more reliable prediction, some other factors that influence the movement of the estimated phenomena need to be considered. Therefore, in the follow-up to the paper, the movement of the number of passengers carried in the railway transport of Kosovo should be viewed from the perspective of various influential factors that the author of the paper has assessed, and they may be relevant to this assessment which is possible using the regression analysis method.

\section{Request for Railway Transport in Kosovo with regression analysis}

Regression analysis is a statistical method that examines the relationships between phenomena. On the one hand there is a phenomenon representing the dependent variable (Y) which will be explained, and on the other hand one or more phenomena that are independent or explanatory variables $(\mathrm{X})$.

The variable whose variations (changes) are explained by other denominations is called the dependent variable. The variables that explain the variation of the dependent variables are called independent variables. The basis of each analysis is the regression model.

The regression model is an algebraic model that analytically expresses the statistical relationships between phenomena. Regression models serve analytical purposes, often for prognostic purposes.

The regression model is an equation or set of equations with a finite number of parameters and variables. More on regression analysis can be seen below [4]. The regression models are presented in general form.

$$
\begin{gathered}
Y=f\left(X_{1}, X_{2}, \ldots, X_{j}, \ldots, X_{k}\right)+e \\
Y=f\left(X_{1}, X_{2}, \ldots, X_{j}, \ldots, X_{k}\right)+\varepsilon
\end{gathered}
$$

Where:

$Y$ - Dependant variable.

$X_{1}, X_{2}, \ldots, X_{j}, \ldots, X_{k}$ - Independent variable (regression, explanation).

$e$ or $\varepsilon-$ Stochastic variables representing non-systematic impacts on the dependent variable, i.e. unknown deviations from the functional relationship.

The functional part of model $f\left(X_{1}, X_{2}, \ldots X_{\mathrm{j}}, \ldots X_{\mathrm{k}}\right)$ is different and depends on the particular application case.

Assuming that the relationship between $Y$ and $\left(X_{1}, X_{2}, \ldots X_{\mathrm{j}}, \ldots X_{\mathrm{k}}\right)$ is linear, the regression model is the multiple linear regression model. 


$$
\begin{gathered}
Y_{i}=a+b_{1} X_{i 1}+b_{2} X_{i 2}+\cdots+b_{j} X_{i j}+\cdots+b_{m} X_{i m}+e_{i} \\
i=1,2, \ldots, n
\end{gathered}
$$

Where:

$Y_{i}-$ Value of the dependant variable,

$X_{i j}(i=1,2, \ldots, \mathrm{n} ; j=1,2 \ldots, \mathrm{m})$ - the value of the independent variables,

$m$ - Number of independent variables $X_{j}$

$a, b_{j}(j=1,2, \ldots, m)$ - Value of unknown parameters,

$e-$ Random variable (the so-called relational error)

Table 2. Regression analysis output: coefficients

\begin{tabular}{|l|l|}
\hline Statistic & Description \\
\hline Slope coefficient & b value in $\mathrm{y}=\mathrm{bx}+\mathrm{a}$ \\
\hline Intercept constant & a value in $\mathrm{y}=\mathrm{bx}+\mathrm{a}$ \\
\hline Standard error of slope & $\begin{array}{l}\text { The standard error value (s) for the b } \\
\text { coefficient(s). }\end{array}$ \\
\hline Standard error of intercept & The standard error value for the constant a. \\
\hline Coefficient of determination $\left(\mathrm{R}^{2}\right)$ & $\begin{array}{l}\text { Indicates how well the regression equation } \\
\text { explains the relationship among the variables. }\end{array}$ \\
\hline Standard error for the Y estimate & Shows the precision of the regression analysis. \\
\hline F statistic, or the F-observed value & $\begin{array}{l}\text { It is used to do the F-test for the null hypothesis } \\
\text { to determine the overall goodness of fit of the } \\
\text { model. }\end{array}$ \\
\hline Degrees of freedom (df) & The number of degrees of freedom. \\
\hline Regression sum of squares & $\begin{array}{l}\text { Indicates how much of the variation in the } \\
\text { dependent variable is explained by the model. }\end{array}$ \\
\hline Residual sum of squares & $\begin{array}{l}\text { Measures the amount of variance in the } \\
\text { dependent variable that is not explained by } \\
\text { regression model. }\end{array}$ \\
\hline
\end{tabular}

In this paper the demand for passenger transport in railway transport in Kosovo is analyzed using multiple linear regression model. For the dependent variable, the passenger transport variable (NPTR) is taken. This paper assumes variables that can statistically significantly explain the way in which the requirements for rail transport in Kosovo moves (Table 1). Different combinations of independent variables resulted in two variants of the regression equations that meet the basic tests of regression analysis (Table 3 ).

\begin{tabular}{|c|c|c|c|c|}
\hline Variant & The regression equation & $\mathbf{R}^{2}$ & $\overline{R^{2}}$ & $\mathbf{F}$ \\
\hline I. VARIANT & $\begin{array}{r}\text { NPTR }=834474-2.439 \text { NVR } \\
(4.32) \quad(-3.13)\end{array}$ & 0.582 & 0.522 & 9.77 \\
\hline II. VARIANT & $\begin{array}{c}\text { NPTR }=1231152+0.782 \mathrm{NVR}-2719.4 \mathrm{AP} \\
(4.07) \quad(0.37) \quad(-1.60)\end{array}$ & 0.708 & 0.610 & 7.27 \\
\hline & \multicolumn{4}{|c|}{$\begin{array}{l}t \text {-value ( empirical t-ratio), } F \text { - empirical F-ratio, } R^{2} \text { - coefficient of determination, } \\
R^{2}-\text { corrected coefficient of determination }\end{array}$} \\
\hline
\end{tabular}

Table 3. Results of regression analysis

The first variant is the simple regression analysis equation. Considering the values of the empirical ratio of the test performed for the independent variable in the model, it was concluded that the estimated parameters are significant, i.e. that the independent NVR variable significantly influences the change in the observed NPTR explanatory variable. 
The coefficient with the NVR regression variable is negative and significant at any significance level, meaning that if the number of registered passenger cars increases, also in three years $(2011,2012,2013)$ the number of passengers transported by rail (NPTR) increased on $1.06 \%$.

From 2014-2019, the number of registered vehicles increased, number of passengers transported by rail decreased for $48.38 \%$. Also, an adjusted coefficient of determination of 0.522 means that the percentage of the sum of the squared deviation interpreted to the sum of the squared deviation is $52.2 \%$. The graphical representation of the first variant of the regression equation is the direction of the regression (Figure 5).

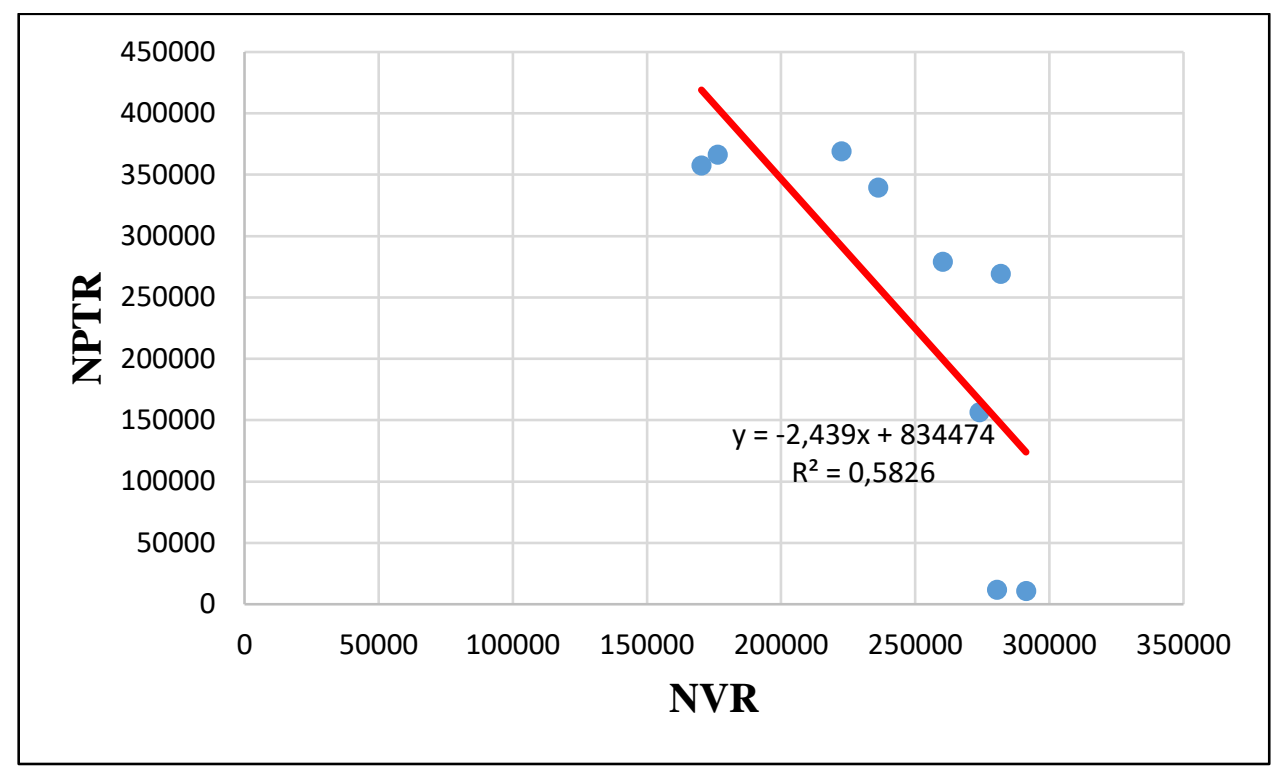

Fig. 5 Distribution diagram with regressive direction, reduction in the number of passengers transported by depending on the number of registered vehicles

Variant II. Refers to the multiple regression analysis equation in which there are two independent variables that explain the changes in the dependent variables on the number of passengers transported by rail (NPTR).

After performing the t-test for some independent individual variables in the model, it was concluded that the estimated parameters are significant, i.e., the independent variables selected Number of Registered Vehicles (NVRs) and Average Payments in Kosovo (APK) significantly affect changes in the explanatory variable of passenger transport in rail transport (NPTR). Both coefficients with independent variables in variant model II, are statistically significant.

Despite the increase in the number of registered vehicles, the number of members transported by rail decreases by an average of over $15 \%$, and before the negative sign of the coefficient of the second independent variable (AP) indicates that the average payments (APK) increases for years the number of passengers in rail transport has been falling.

The adjusted coefficient of determination indicates that $61 \%$ of all deviations are interpreted by this model, while the empirical $F$ ratio of 7.27 at each significance level guides the conclusion regarding the significance of the regression.

The dependence of the variables evaluated in this example can be explained in different ways, and one of the possible explanations is by calculating the correlation coefficient 
However, the NPTR dependent variable and the independent NVR variable are in linear relationship, which further means that by decreasing one variable we have the increase of the other variable and vice versa.

From the data in Table 1 it follows that the number of passengers from 2011 to date has been continuously decreasing (decreasing), especially the sharp decline since 2014 when our country is hit by the global economic crisis, and the situation created in the Balkans.

The same is true for the number of registered passenger cars where there has been a relatively increase in the number since 2011, however, the NPTR variable is negatively correlated with the APK variable $(-0,897)$, from which it can be concluded that with the increase in pay average net passenger transport is expected to fall by rail, possibly due to the high potential for individual highway transport

One of the basic purposes of regression analysis is forecasting. Under the "prognostic" value of $\mathrm{Y}$ variables, based on the regression model, is its estimated value for the new (real and assumed) value of the regression variables.

Since the statistical fit of the model choice fit is satisfactory for both variants of the regression analysis, the simple regression analysis equation is solved:

NPTR $=834474-2.439 \cdot$ NVR which can be used to describe the number of passengers transported by rail, and to make further predictions.

Estimated values of the independent NVR variable for the period 2011-2019. Based on the third-degree parabolic trend, for which it was previously confirmed to have the highest representation $(69 \%)$, given in Table 4.

Table 4. Forecast of registered passenger vehicles, and passenger transport in railway transport in Kosovo, from 2015 to 2019

\begin{tabular}{|c|c|c|}
\hline Year & NVR & NPTR \\
\hline 2015 & 281847 & 269150 \\
\hline 2016 & 260291 & 279210 \\
\hline 2017 & 273862 & 156620 \\
\hline 2018 & 280422 & 12030 \\
\hline 2019 & 291295 & 11024 \\
\hline
\end{tabular}

By including these values in the regression equation, values that are interpreted as predicting the number of passengers in rail transport in Kosovo from 2011 to 2019 are obtained (Table 4).

Based on forecast data for the next five-year period, it can be concluded that the number of registered passenger cars in the next two to three years tends to decline, which is understandable as Kosovo at least it will still be in a severe economic crisis, and even when some economic progress is made, the stagnation in the growth of any personal consumption will continue to increase, especially in the so-called, the luxury need.

However, according to forecasts for the number of passengers transported by rail, it is clear that this number tends to decline as time does not present other opportunities which in a snap way make passenger transport more demanding, rational, and however, it is competitive with other modes of transport, especially the one which is the most widely used one today. 


\section{CONCLUSION}

In conducting the analysis of passenger transport demand in rail transport, the aim of the paper was to determine its intensity and structure and to investigate which factors have the greatest impact on passenger demand for rail transport. The subject of the research is limited to the transportation of passengers in domestic rail transport in Kosovo. Using quantitative methods of time series analysis and regression analysis, the movement was determined and the demand for passenger rail transport assessed. Different combinations of variables and dependencies were investigated, and it was finally concluded that the number of passengers in rail transport depends on the number of registered passenger cars and the average payment in the Kosovo.

It was also found that in the period analysed from 2011 until today, these variables tend to decline, which is particularly pronounced from 2015 to the present, and the forecast results indicate their further decline, i.e. stagnation, assuming that this will last until Kosovo emerges from the great economic crisis and then until the market stabilization period which directly affects the movement of the variables evaluated in this paper.

In spite of the achieved results, this paper leaves place for further research on this problem with the possibility of introducing more variables and eventual combination with any qualitative and quantitative methods that would enable new and efficient knowledge in problem research.

\section{REFERENCES}

[1] Mazrekaj, R. "Study of Integration of Kosovo's road network in Pan European Network Aimed at Sustainable Development of transport in the Balkan region", PhD thesis, Tirana, Albania, 2010.

[2] SEETO "Network Comprehensive Development Plan 2012 - Multiannual Plan 20122016“, www.seetoint.org/library/multi-annual-plans/

[3] Mazrekaj, R. "The Importance of Geographical Position of Kosovo in Increased Trade, Transit and International Transport in the Balkans", IFAC-PapersOnLine 49 (29), pp. 315 - 319, 2016. DOI: 10.1016/j.ifacol.2016.11.086

[4] Ortúzar, J. D., Willumsen, L. G. "Modelling transport", John Wiley \& Sons, $4^{\text {th }}$ edition, 2011.

[5] Louis Berger, SA. "Transport Infrastructure Regional Study (TIRS) in the Balkans", 2002.

[6] Enders, W. "Applied Econometric Time Series", 2nd edition, John Wiley\&Sons, New York, 2004.

[7] Hess, S. "Planiranje prometne potražnje“, Pomorski fakultet u Rijeci, Sveučilište u Rijeci, Rijeka 2010.

[8] Hoxha, G., Shala, A., Likaj, R. "Vehicle speed determination in case of road accident by software method and comparing of results with the mathematical model", Strojnícky časopis - Journal of Mechanical Engineering 67 (2), pp. 51 - 60, 2017. DOI: 10.1515/scjme-2017-0017

[9] Valkovič, V., Jančo, R., Frydrýšek, K. "The effect of landslide on gas pipeline“, Strojnícky časopis - Journal of Mechanical Engineering 66 (2), pp. 95 - 100, 2016. DOI: 10.1515/scjme-2016-0023

[10] Johnson, R. A., Wichern, D. W. "Applied Multivariate Statistical Analysis“, 6th edition, Pearson, Prentice Hall, New York, 2007. 
[11] Brčić, D., Ševrović, M. "Logistika prijevoza putnika, Fakultet prometnih znanosti“", Zagreb, 2012.

[12] Pajden, J. “Osnove prometnog planiranja, Informator", Zagreb, 1986.

[13] Šlesar P., Jančo R. "Press-Fit Evaluation and Study of Displacement in Temperature Changes", Strojnícky časopis - Journal of Mechanical Engineering 68 (1), pp. 103 - 108, 2018. DOI: $10.2478 /$ scjme-2018-0011

[14] Poduška, J., Hutař, P., Frank, A., Kučera, J., Sadílek, J., Pinter, G., Náhlík, L. "Soil Load on Plastic Pipe and its Influence on Lifetime“, Strojnícky časopis - Journal of Mechanical Engineering 69 (3), pp. 101 - 106, 2019. DOI: 10.2478/scjme-2019-0036

[15] "Multimodal Transport and Sector Strategy 2015-2025 , and 5 year Action Plan“, Ministry of Infrastructure, Kosovo, 2015.

[16] Krasniqi, R., Doci, I., Shala, A., Berisha, R. "Regulation of Traffic Flow in Small Cities with High Number of Vehicles: Case of Malisheva City - Kosovo", International Review of Civil Engineering (IRECE) 9 (4), pp. 161 - 167, 2018. DOI: 10.15866'irecev9i4.14300

[17] "Kosovo Railways", Pristina, R. Kosovo, www.trainkos.com and www.ifrakos.com 2019-21. 